\title{
Performance Assessment of Dispersion Compensation Using Fiber Bragg Grating and Dispersion Compensation Fiber Techniques
}

\author{
Guruviah Karpagarajesh ${ }^{1}$, Alice Blessie ${ }^{1}$, Santhana Krishnan ${ }^{2}$
}

${ }^{1}$ Department of Electronics and Communication Engineering, Government College of Engineering, Tirunelveli, Tamilnadu, India

${ }^{2}$ Department of Electronics and Communication Engineering, SCAD College of Engineering and technology, Tirunelveli, Tamilnadu, India

\begin{abstract}
Dispersion should be flattened to achieve the most optimal output of the contact device. Since dispersion induces pulse spreading, which causes the output signal pulses to overlap, dispersion compensation is the most important attribute needed in an optical fiber communication device. A unique dispersion compensation system for a long-haul transmission system with a 5 Gbit/s data rate for each channel has been devised in this paper employing Fiber Bragg Grating (FBG) and Dispersion Compensation Fiber (DCF). The performance of dispersion compensation is evaluated using both grating and non-grating techniques. In this, primarily the proposed system is implemented without applying the grating technique and the outcomes are simulated and analyzed. Subsequently, the system is designed and implemented with FBG and DCF and the outcomes are simulated with opti-system-16.0 software. The proposed scheme is simulated with the 32768 numeral of samples with a bit rate of $109 \mathrm{bits} / \mathrm{sec}$. The optical fiber's length can range from 50 to 200 kilometers. The parameters like Q-factor, Bit Error Rate (BER) and Signal to Noise Ratio (SNR) were simulated and calculated by exploiting the 8-channel device. With minimal 0.6 dB/km attenuation, FBG achieves a Q-factor of 288.335 and DCF achieves a Q-factor of 284.994 for $8 \times 1$ WDM MIMO communication systems with a 5 Gbit/s data rate. At the receiver end of systems, the suggested model improves performance in terms of bit error rate (BER) and quality factor.
\end{abstract}

Keywords: FBG; DCF; BER; Q-factor; WDM

\section{Ocena učinkovitosti kompenzacïje disperzije z uporabo Braggovih vlaknatih rešetk in kompenzacijo disperzije z vlakni}

\begin{abstract}
Izvleček: Disperzija mora biti izravnana, da se doseže najbolj optimalen izkoristek kontaktne naprave. Ker disperzija povzroča širjenje impulzov, zaradi česar se impulzi izhodnega signala prekrivajo, je kompenzacija disperzije najpomembnejša lastnost, ki je potrebna v komunikacijski napravi iz optičnih vlaken. V tem članku je bil zasnovan edinstven sistem za kompenzacijo disperzije za prenosni sistem na dolge razdalje s hitrostjo prenosa podatkov 5 Gbit/s za vsak kanal, ki uporablja FBG (Fiber Bragg Grating) in DCF (Dispersion Compensation Fiber). Učinkovitost kompenzacije disperzije je ocenjena z uporabo tehnik z rešetkami in brez njih. Pri tem je predlagan sistem izveden predvsem brez uporabe tehnike rešetk, rezultati pa so simulirani in analizirani. Nato je sistem zasnovan in izveden s FBG in DCF, rezultati pa so simulirani s programsko opremo opti-system-16.0. Predlagani sistem je simuliran s 32768 vzorci s hitrostjo prenosa 109 bitov/sek. Dolžina optičnega vlakna je lahko od 50 do 200 kilometrov. Parametri, kot so Q-faktor, stopnja bitne napake (BER) in razmerje med signalom in šumom (SNR), so bili simulirani in izračunani z uporabo 8-kanalne naprave. Z minimalnim slabljenjem 0,6 dB/km doseže FBG Q-faktor 288,335, DCF pa 284,994 za komunikacijske sisteme 8 × 1 WDM MIMO s hitrostjo prenosa podatkov 5 Gbit/s. Na sprejemni strani sistemov predlagani model izboljša učinkovitost v smislu BER in faktorja kakovosti.
\end{abstract}

Ključne besede: FBG; DCF; BER; Q-faktor;WDM

*Corresponding Author's e-mail:gkrajesh1@gmail.com

How to cite:

G. Karpagarajesh et al.,"Performance Assessment of Dispersion Compensation Using Fiber Bragg Grating and Dispersion Compensation Fiber Techniques", Inf. Midem-J. Microelectron. Electron. Compon. Mater., Vol. 51, No. 4(2021), pp. 215-223 


\section{Introduction}

The introduction of WDM systems has expanded the spectrum of optical fiber's application to meet the requirements of high-speed, high-bandwidth, and high-capacity networks. Multiple signals with various wavelengths can be transmitted through WDM networks. At the same time, different signals from different users of different wavelengths are multiplexed in these networks [1]. The optical communication system transfers data from one place to another through light signals. Before being launched into the optical fiber, data or information in the form of an electrical signal is transferred into a light signal. The Transmitter, optical fiber, and Receiver are all components of the system. Depending on the application, the optical fiber used can be multimode or Single-Mode Fiber (SMF). SMF (Single-Mode Fiber) is used extensively in this paper [2].

Because optical fiber communications are a significant and quickly evolving technology, it's reasonable to compare their development to that of radio transmission over a century ago. Spark-gap transmitters and rudimentary receivers were used in the early days of radio. Optical fiber communications began about 25 years ago using directly modulated Light Emitting Diodes and lasers whose optical signal spectrum was far wider than the information bandwidth, similar to early radio systems. The vacuum-tube amplifier was a significant breakthrough in radio communications. [3]

Indeed, the race for faster speeds, higher quality, and massive capacity continues to drive significant advancement in the field of optical communications. Multilevel modulations, polarization multiplexing, coherence detection, and digital processing all play a key role in this regard, as they support and complement each other [4]. The current, well-established scheme of General Multiprotocol Label Switching (GMPLS) will be superseded by telecommunication traffic Software Defined Networking (SDN). This will make the deployment of programmable transponders easier, as well as the network's flexibility and management. [4]

The technique of dispersion compensation is used in fiber optic communication systems to deal with the dispersion introduced by the optical fiber. A light wave moving within the fiber is widened due to dispersion. Two consecutive pulses overlap due to the broadening of the pulse, creating Inter Symbol Interference (ISI). The receiver is unable to differentiate between two symbols due to ISI. This causes symbol recognition errors. It is for this purpose that dispersion compensation is necessary. Dispersion compensation can be done using a range of techniques, including Dispersion Compensating Fiber (DCF), Optical Filter, Fiber Bragg
Grating (FBG), Optical Phase Conjugation, Electrical Dispersion Compensation, and so on [5]. Since DCF and FBG are commonly used techniques, these papers focus on them.

\subsection{Fiber Bragg Grating (FBG)}

FBG is a compensator for dynamic dispersion. At multiple wavelength variations, the FBG system can compensate for chromatic dispersion. As a result, it is the favored method of compensating for chromatic dispersion. The chirped FBG is based on the diffraction grating theory. Inside the propagating medium, Bragg gratings have a periodic variation of refractive index. The grating's chirped FBG allows it to reflect various wavelengths at different points along its length. As a result, it causes various delays for any of the different frequencies or wavelengths [5]. The shorter wavelength (blue light region) will arrive at the FBG first and will be mirrored higher up the FBG, where its Bragg condition will be met. As a result, the shorter wavelength has a longer delay [6]. The longer wavelength (red light region) would have a shorter delay because it travels slower. As a result, the pulse would be un-distributed at the circulator.

Although FBG filters are a cost-effective method for suppressing one of the sidebands in optical double sideband (DSB) modulation schemes, they lack flexibility in terms of adjusting the optical carrier wavelength [7]. Because chromatic dispersion is zero at $1310 \mathrm{~nm}$, it could be another option for avoiding the power cost. The downside of employing the $1310 \mathrm{~nm}$ wavelength is that optical losses are higher than for the $1550 \mathrm{~nm}$ wavelength $(0.2 \mathrm{~dB} / \mathrm{km}$ for $1550 \mathrm{~nm}$ and $0.35 \mathrm{~dB} / \mathrm{km}$ for $1310 \mathrm{~nm})[7]$.

\subsection{Dispersion Compensation Fiber (DCF)}

Dispersion compensating fiber is a simple and effective way to upgrade single-mode fiber links that have already been built [8]. Negative dispersion-compensating fibers have a negative dispersion of $300 \mathrm{ps} / \mathrm{nm} / \mathrm{km}$ and can be used to compensate for transmission fiber's positive dispersion. Group velocity dispersion, Kerr nonlinearity, and the accumulation of amplified random emission noise due to intermittent amplification all contribute to performance degradation in the optical WDM system. System output is dependent on the power levels at the input of various types of fibers, the location of the DCF, and the amount of dispersion due to the nonlinear nature of propagation [8]. Pre, post, and symmetrical compensation schemes are the three types of compensation schemes in which the DCF is mounted before, after, or symmetrically around the SMF. To minimize the size of a DCF, it should have low 
insertion loss, low polarization mode dispersion and low optical nonlinearity, as well as a high chromatic dispersion coefficient [8].

To distribute a power-penalty-free millimeter-wave signal in the radio access network, a unique flexible technique with a single-loop optoelectronic oscillator at the sending end and a configurable dispersion-compensation module at the receiving ends is presented. One solution to the power penalty would be to replace the existing infrastructure with a dispersion-shifted fiber (DSF) instead of a conventional G.652D single-mode fiber. This is the most expensive option, but it provides wideband RF capabilities. However, it is limited in terms of optical wavelength since any deviation from the DSF's zero-dispersion wavelength results in chromatic dispersion effects [9].

\section{Proposed methodology}

The WDM 8*1 MIMO channel with compensation using Fiber Bragg Grating (FBG) and dispersion compensation fiber (DCF) is depicted in Figure 1. The block diagram is alienated into three subsystems: transmitter, receiver, and channel. The transmitter sub-block is made up of $8 * 1$ input channels that go through a WDM (Multiplexer) MUX. The MUX signal travels through the channel, which is made up of optical fiber, an EDFA amplifier, FBG and DCF compensation techniques. The receiver sub -block consists of WDM, (Demultiplexer) DEMUX, and the received signal is transferred to the output channels in the final stage.

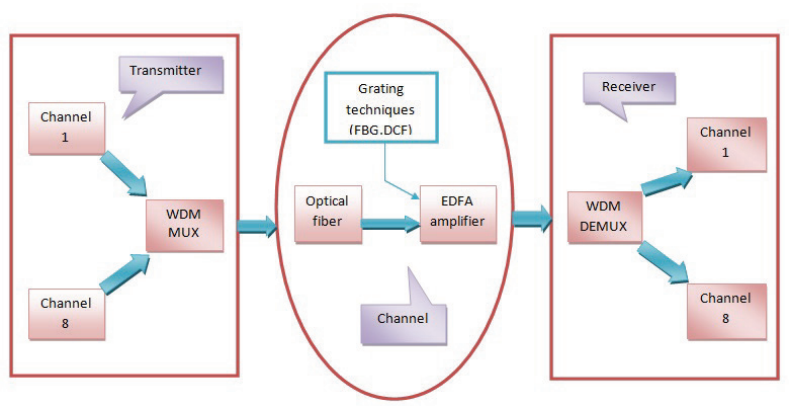

Figure 1: Block diagram of WDM MIMO $8 \times 1$ channel with Compensation techniques using (FBG and DCF).

Figure 2 shows the subsystem of the WDM transmitter in which the Pseudo-Random Bit sequence generates sequence random bits ( 0 or 1 ). Due to the generator's characteristic of returning signals to zero between bits, the Non-return-to-zero (NRZ) pulse generator has the benefit of controlling bandwidth. In terms of bit rates, a pseudo-random bit sequence generator is used to scramble data signals. The Mach-Zehnder Modulator

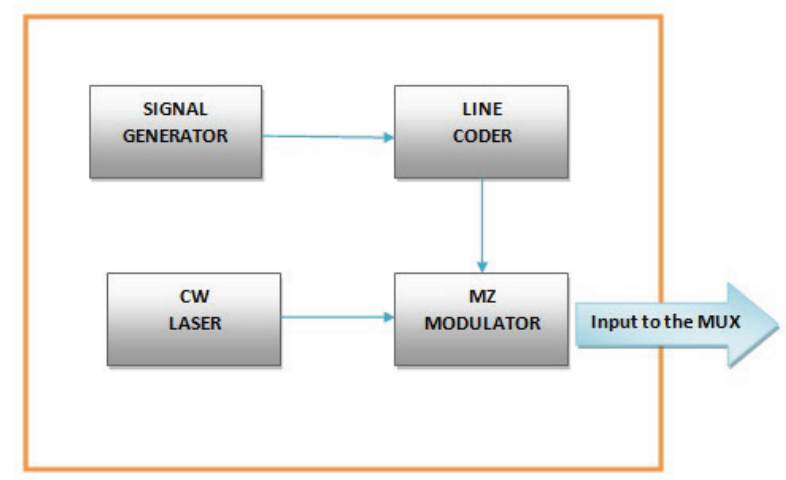

Figure 2: Subsystem of WDM transmitter

(MZM) has one output and two inputs (optical and electrical signals). A semiconductor laser represented by a Continuous Wave (CW) laser modulates the input signal via a Mach-Zehnder Modulator.

To produce optical signals, a continuous laser diode provides an input signal with a wavelength of $1550 \mathrm{~nm}$ and a $5 \mathrm{dBm}$ input power that is externally modulated at $10 \mathrm{Gbit} / \mathrm{s}$.

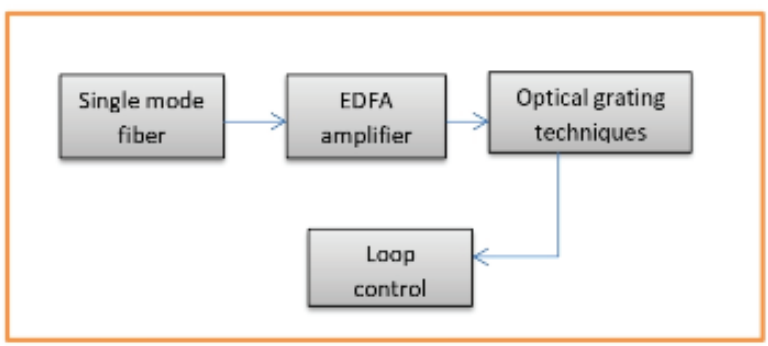

Figure 3: Optical fiber channel design installed with grating technique

Figure 3 shows the optical fiber channel design installed with the grating technique. Single-mode optical fiber is deployed as a transmission network because it has a faster data rate, less dispersion, and can be used over long distances. In the proposed model, the grating length is $6 \mathrm{~mm}$. Optical amplification is sufficient to tackle fiber loss and enhance the signal before it is received by the PIN diode in the receiver segment.

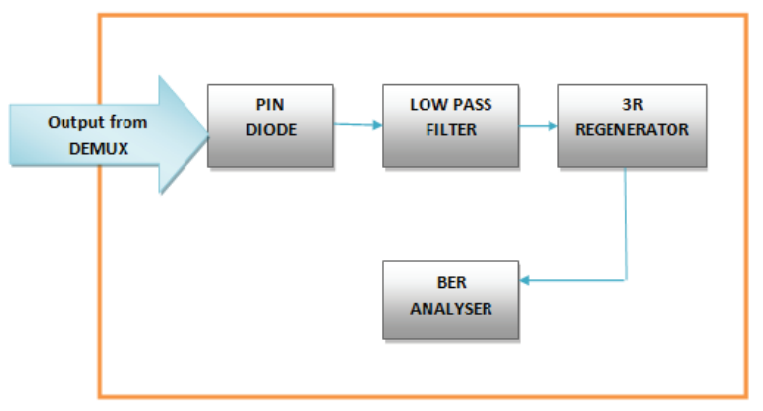

Figure 4: Receiver Sub block 
Figure 4 illustrates the receiver sub-block of the $8 \times 1$ channel in which the Positive Intrinsic Negative (PIN) diode translates the optical signal into an electrical signal. One photon yields one electron. After the modulation, high-frequency noises are eliminated using filters. Bessel filter provides flat propagation. Low pass Bessel filter has flat phase and group delay. This has shallow frequency bands. The order of the low pass filter is 4 . Bessel filter has the transfer function [10] as follows

$$
\begin{aligned}
& \mathbf{H}(\mathbf{S})=\frac{\boldsymbol{a d}}{\boldsymbol{B}_{N}(\boldsymbol{S})} \\
& \boldsymbol{d}_{0}=\frac{(2 \boldsymbol{N}) !}{2^{N} \boldsymbol{N} !}
\end{aligned}
$$

where $H(s)$ represents the transfer function, $\mathbf{a}$ is the parameter insertion loss of unit in $\mathrm{dB}, \mathrm{N}$ is the parameter order, and $B_{N}(s)$ an nth-order Bessel polynomial. BER visualizer allows the user to calculate and display the bit error rate (BER) of an electrical signal automatically. BER visualizer can estimate the BER using different algorithms such as Gaussian and Chi-Squared.

The flow chart of the proposed system is shown in figure 5. The simulation layout of FBG, DCF, transmitter subsystem, and receiver sub-system is shown in figure 6 and figure 7.

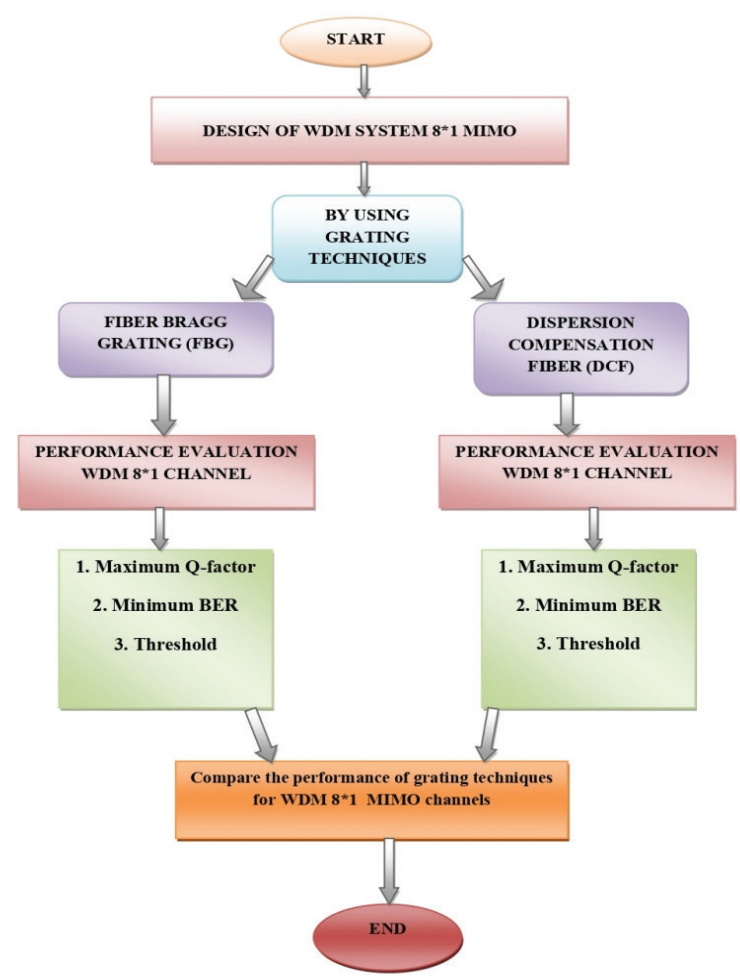

Figure 5: Flow chart of the proposed system

\subsection{Flow chart}

Figure 5 symbolizes the flow chart of the proposed system. The flow chart is intended to help visualizing the

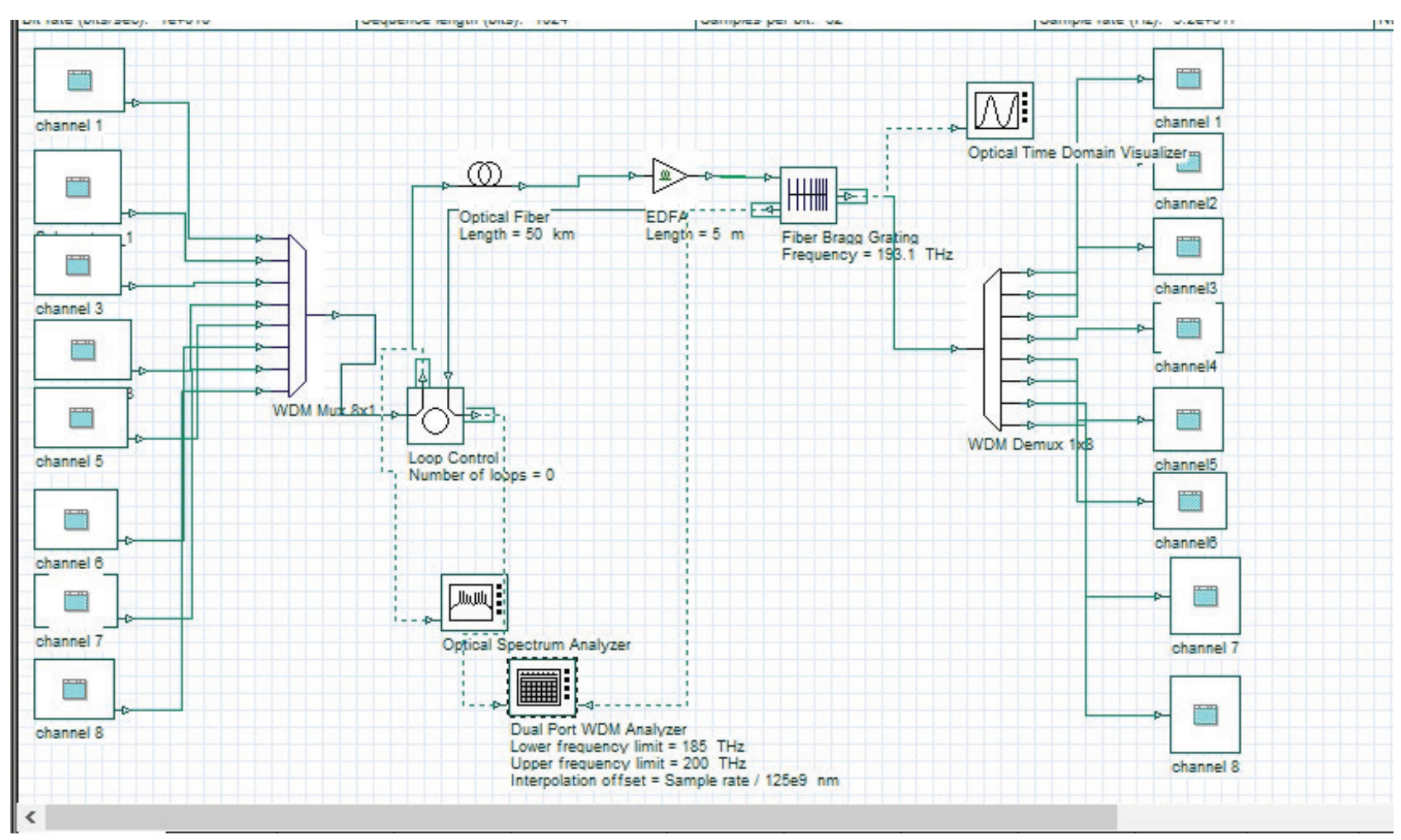

Figure 6: Simulation layout diagram of FBG in WDM system 


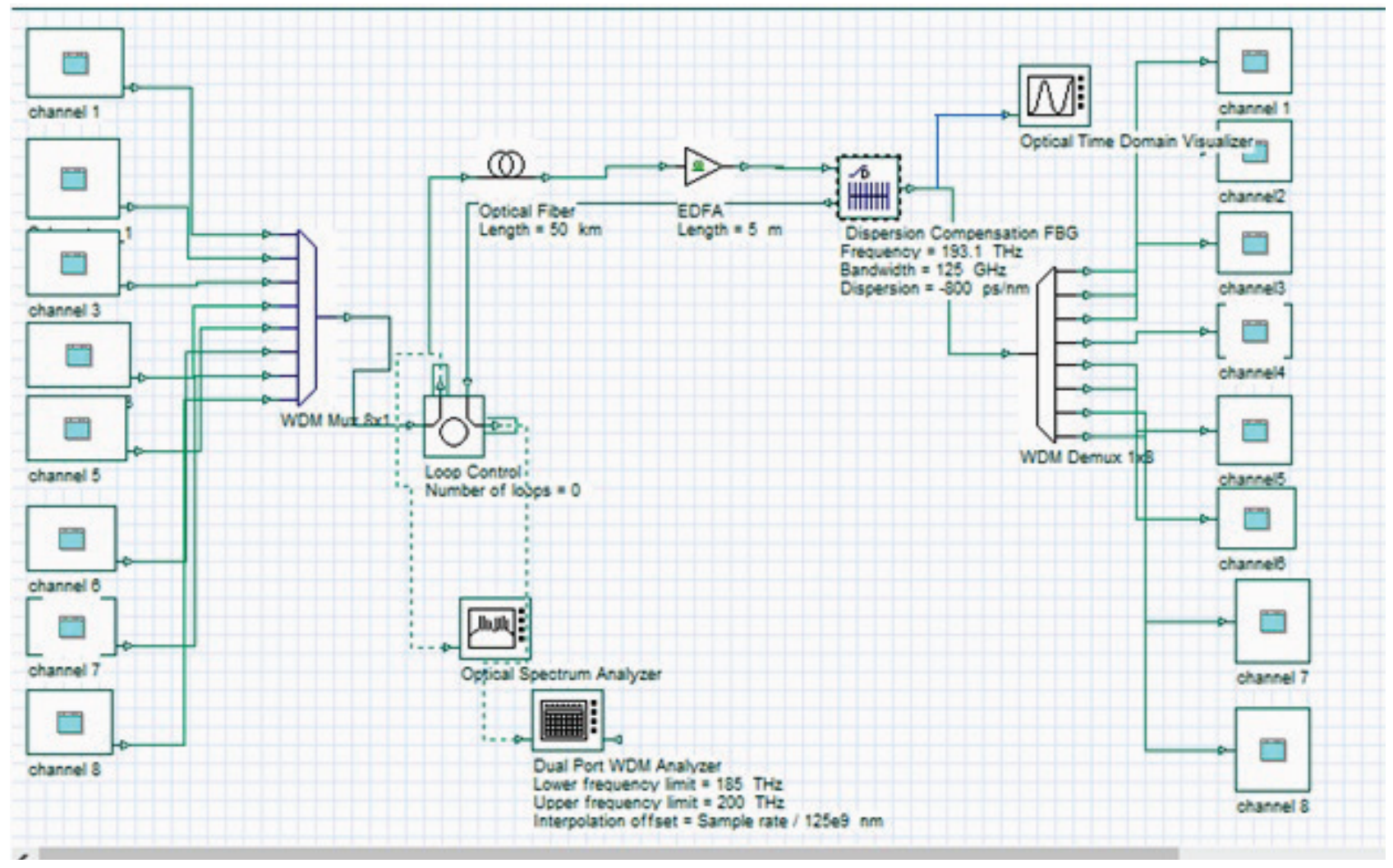

Figure 7: Simulation layout diagram of DCF in WDM system

proposed system. The proposed WDM system is made up of $8 \times 1$ WDM Multi Input Multi Output communication systems with a data throughput of $5 \mathrm{Gbit} / \mathrm{s}$. The outcomes are simulated and analyzed.

Both grating and non-grating methodologies are used to evaluate the performance of dispersion compensation. The proposed system is first developed using a non-grating technique. In this proposed system, two grating techniques have been designed and implemented. They are FBG and DCF. The performance of both grating techniques was compared to that of a non-grating technique, and measures such as Q-factor, Bit Error Rate, and Signal to Noise Ratio were examined.

\subsection{Layout}

Figure 6 and 7 shows the simulation layout diagram of fiber Bragg grating and dispersion compensation fiber. This layout indicates the transmitter subsystem of 8 channels. The optical signal from the output of the transmitter is then directed in the direction of the WDM $8^{*} 1$ multiplexer channels with the assist of an optical fiber. An optical receiver subsystem accepts the incoming signal as part of the WDM de-multiplexer system's receiver output. The signal is then directed in the direction of an avalanche photodiode (APD) which converts the optical sign into its electric counterpart. The APD photodiode is accompanied with the aid of using a Bessel low-pass filter which eliminates any high-frequency noise present inside the obtained signal.

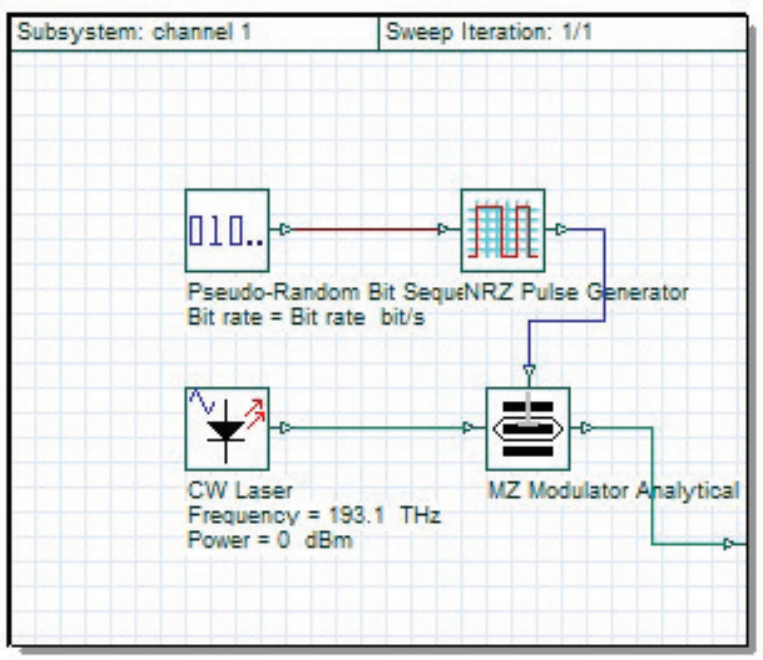

Figure 8: Layout diagram of Transmitter subsystem

Figure 8 confirms the layout of the transmitter subsystem which comprises a pseudorandom pulse generator that produces the information to be broadcasted in the structure of binary data. Binary data is fed into an NRZ pulse generator, which converts it into electrical pulses for transmission. The output of the NRZ pulse generator 
is directed to an MZM, which modulates the electrical pulses with a 1,550 $\mathrm{nm}$ continuous wave laser.

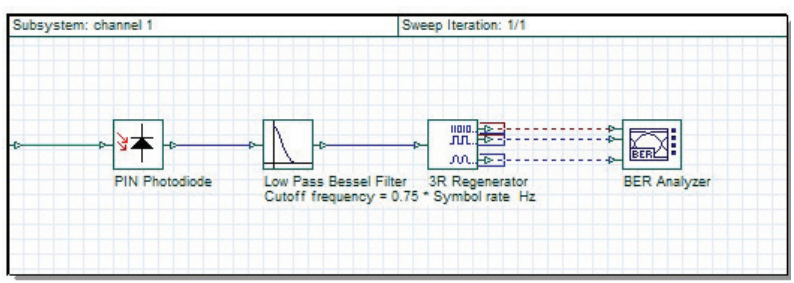

Figure 9: Layout diagram of Receiver subsystem

Figure 9 reveals the layout of the receiver subsystem which has a PIN diode accompanied with the aid of using a Bessel low-pass filter which eliminates any highfrequency noise present inside the obtained signal.

\section{Results and discussion}

This section presents the details of the experiment carried out for implementation. The system was simulated with opti-system-16.0 software. The simulation parameters used for developing the model are shown in Table 1 and Table 3.

\subsection{Result analysis of Non-Grating technique}

Initially, the proposed system is implemented for the non-grating technique. The outcomes are simulated and analyzed. The following figure shows the eye diagram of the non-grating technique of the proposed system. Figure 10 furnishes a small eye-opening in the eye diagram which means that the Inter Symbol Interference (ISI) is high.

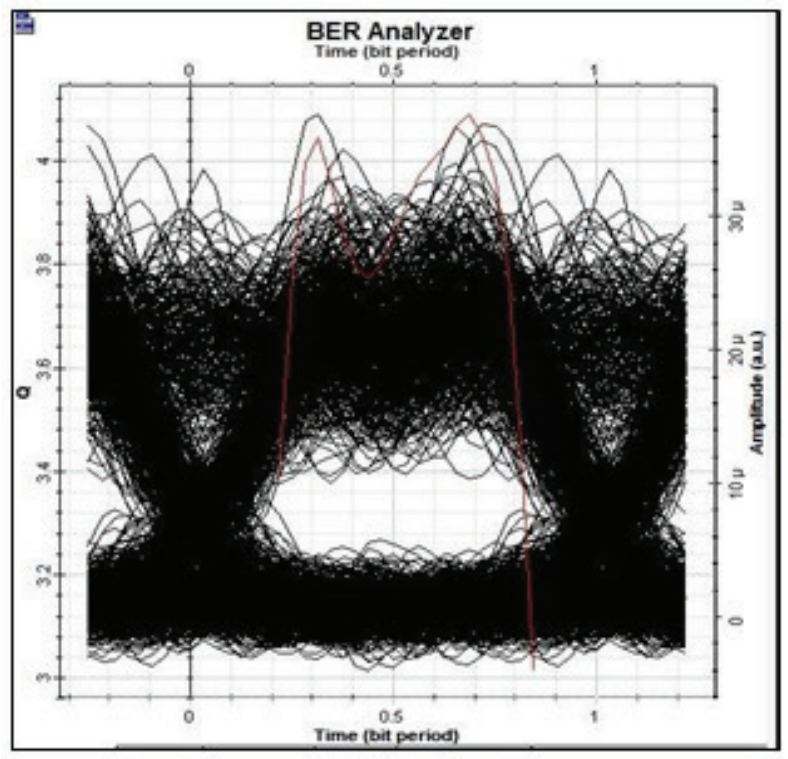

Figure 10: Result of non-grating technique
The simulation for the non-grating technique is done to analyze the $\mathrm{Q}$ factor of the single mode fiber $8 \times 1$ WDM channels. The results revealed a decrease in quality factor with slightly increased BER shown in Figure 10. To avoid dispersion and high inter-symbol interference, the proposed system is designed and simulated by using FBG and DCF techniques.

\subsection{Fiber Bragg Grating simulation parameters}

The simulation parameters of fiber Bragg gratings are indicated below.

Table 1: Parameters and their values

\begin{tabular}{|l|c|}
\multicolumn{2}{|c|}{ FIBER BRAGG GRATING } \\
\hline Parameters & Values \\
\hline Frequency & $193.1-193.8 \mathrm{THz}$ \\
\hline Effective index length & 1.45 \\
\hline Noise threshold & $-100 \mathrm{~dB}$ \\
\hline Noise dynamic & 101 \\
\hline Number of segments & 1000 \\
\hline $\begin{array}{l}\text { Maximum number of } \\
\text { spectral path }\end{array}$ & \\
\hline
\end{tabular}

Table 1 depicts the simulation parameters deployed to implement the proposed WDM system. Table 1 signifies the simulation inputs of FBG used in the proposed system. The values given in table 1 are attained using the trial and error method. Continuous Wave Laser (CWL) is used as the source with the transmitter frequency of 193.1 THz. The proposed system is simulated with the 32768 number of samples with a bit rate of $109 \mathrm{bit} / \mathrm{sec}$. $100 \mathrm{GHz}$ of transmitter frequency spacing with $15 \mathrm{dBm}$ of transmitter power is taken. The wavelength used for simulation is $1550 \mathrm{~nm}$. The proposed system consists of a $5 \times 8 \mathrm{Gbit} / \mathrm{s}$ WDM system with 8 channels sending 5 Gbit/s each with channel spacing $100 \mathrm{GHz}$. NRZ formatting is done in these 8 channels and is multiplexed at the transmitter side.

\subsection{Result Analysis of FBG}

Using FBG, the proposed system is simulated and the values are tabulated below.

Table 2: Outcomes of FBG in WDM system

\begin{tabular}{|l|c|c|c|}
\hline Distance in km & Maximum Q-factor & BER & SNR \\
\hline 50 & 288.335 & 0 & 61.704 \\
\hline 100 & 287.516 & 0 & 61.626 \\
\hline 150 & 286.176 & 0 & 61.669 \\
\hline 200 & 285.096 & 0 & 61.68 \\
\hline
\end{tabular}


Table 2 shows the FBG outputs obtained in the WDM system. These outputs are obtained with the varied inputs given in table 1.Table 2 reveals the outcome of FBG in the WDM system which has the Max Q-factor, minimum bit error rate (BER). The outcome of FBG shows the maximum Q-factor of 288.335 obtained at a distance of $50 \mathrm{~km}$. As the distance increases, Q-factor decreases with reduced SNR. BER is reduced to a minimum though the distance increases.

\section{Eye Diagram of FBG}

The eye diagram of FBG in terms of quality factor and BER is discussed below. Figures $11 \& 12$ represent the $Q-$ factor and BER curve for using Fiber Bragg grating with a maximum $Q$ factor of 288.335 and a minimum $Q$ factor of 286.176 respectively.

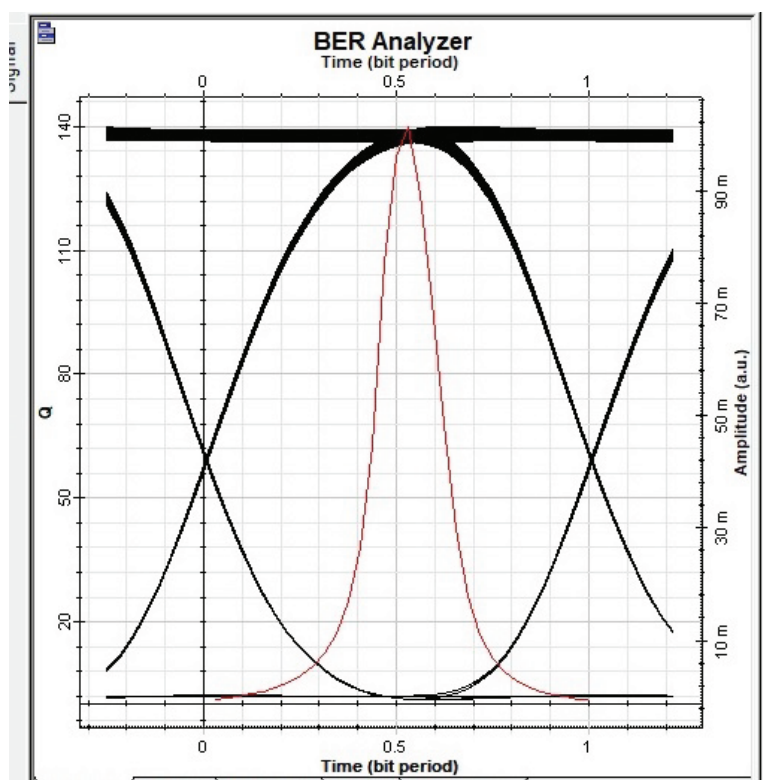

Figure 11: Eye diagram of FBG

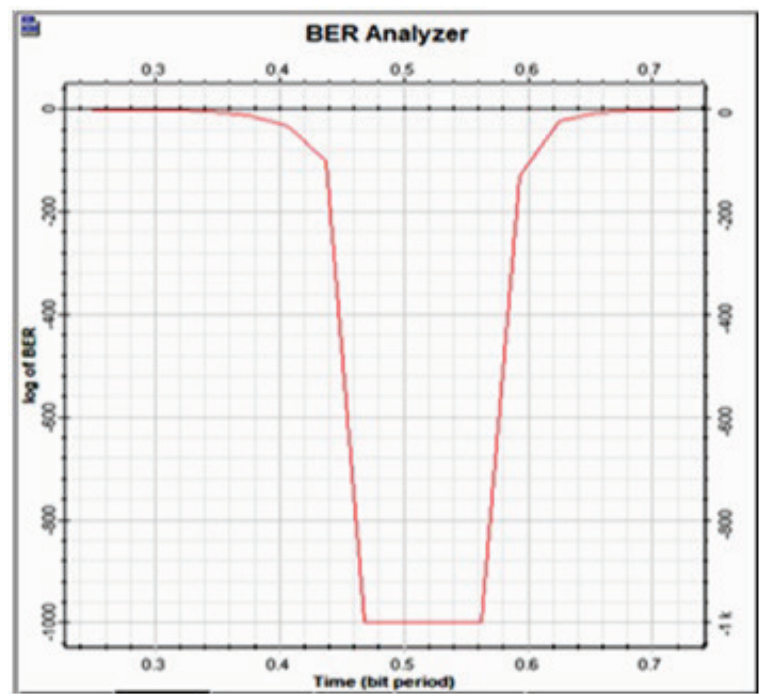

Figure 12: BER curve of FBG over bit period
The channel outcomes for using grating techniques in terms of eye diagrams are shown above. Q-factor represents the quality of the SNR in the 'eye' of a digital signal, the "eye" being the human eye-shaped pattern on an oscilloscope that indicates transmission system performance. The best place for determining whether a given bit is a "1" or a " 0 " is the sampling phase with the largest "eye-opening". The larger eye-opening, the greater the difference between the mean values of the signal levels for a " 1 " and a " 0 ". The greater that difference is the higher the Q-factor and the better the BER performance. Q- Factor is usually defined as the eyeopening (difference between upper and lower signal levels) divided by the sum of the individual noise standard deviations on the two levels.

\subsection{Dispersion Compensation fiber}

The simulation parameters of dispersion compensation fiber are indicated below.

Table 3: Simulation parameter of DCF used in the proposed system

\begin{tabular}{|l|c|}
\hline \multicolumn{2}{|c|}{ DISPERSION COMPENSATION FIBER } \\
\hline Parameters & Values \\
\hline Differential group velocity & $3 \mathrm{ps} /(\mathrm{nm} \mathrm{km})$ \\
\hline PMD coefficient & $0.5 \mathrm{ps} / \mathrm{km}^{1 / 2}$ \\
\hline Reference wavelength & $1550 \mathrm{~nm}$ \\
\hline Attenuation & $0.6 \mathrm{~dB} / \mathrm{km}$ \\
\hline Dispersion & $-80 \mathrm{ps} / \mathrm{nm} / \mathrm{km}$ \\
\hline Effective area & $30 \mu \mathrm{m}^{2}$ \\
\hline
\end{tabular}

Table 3 depicts the simulation parameters of DCF deployed to implement the proposed system. Table 3 signifies the simulation inputs of DCF used in the proposed system. The values given in table 3 is attained using the trial and error method

\subsection{Result Analysis of DCF}

Table 4: Outcomes of DCF in WDM system

\begin{tabular}{|l|c|c|c|}
\hline Distance in km & Max Q-factor & BER & SNR \\
\hline 50 & 284.994 & 0 & 61.655 \\
\hline 100 & 283.765 & 0 & 61.535 \\
\hline 150 & 284.761 & 0 & 61.684 \\
\hline 200 & 282.356 & 0 & 61.66 \\
\hline
\end{tabular}

Table 4 reveals the outcome of DCF in the WDM system which has the maximum Q-factor, minimum bit error rate (BER). The outcome of FBG shows the maximum Q-factor of 284.994 obtained at a distance of $50 \mathrm{~km}$. As the distance increases, Q-factor decreases with reduced SNR. BER are reduced to minimum though the distance increases. 
The Q-factor and BER curves for dispersion compensating fiber are shown in Figures 13 and 14. The obtained $Q$ factor of 284.994 is greatest at a distance of $50 \mathrm{~km}$ and a Minimum Q factor of 286.155 is obtained at $200 \mathrm{~km}$ distance respectively.

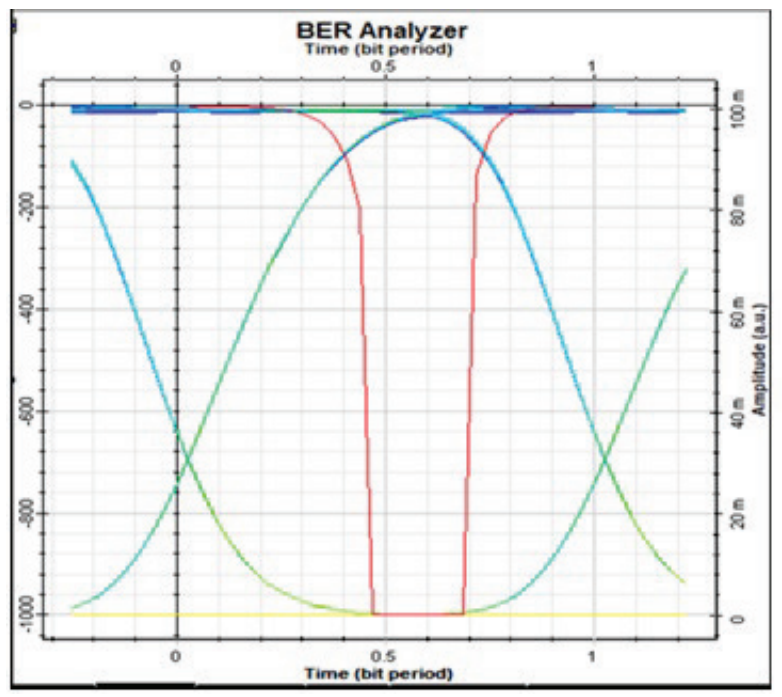

Figure 13: Eye diagram of DCF

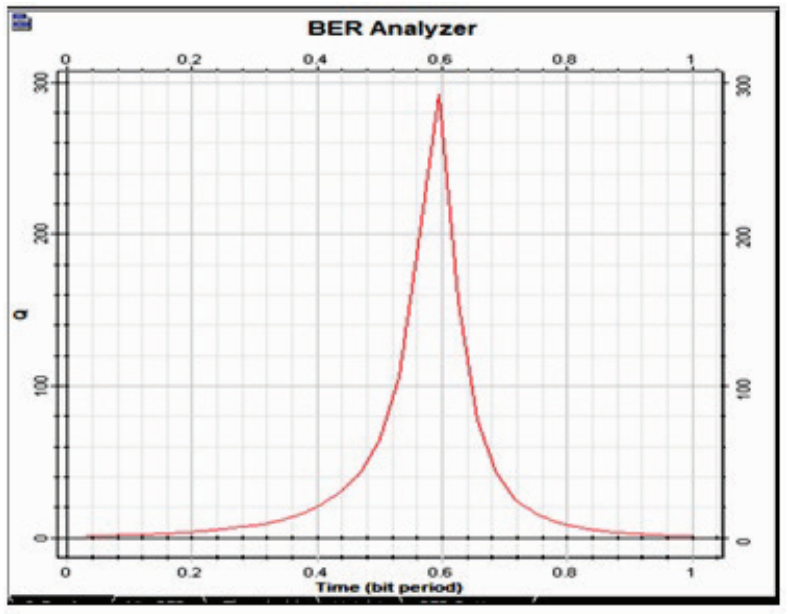

Figure 14: Q-factor of DCF over bit period

\subsection{Comparative analysis of FBG, DCF and Non- grating techniques}

The overall comparative $\mathrm{Q}$ factor analysis of all three techniques are tabulated and shown below.

Table 5: Comparative analysis of Q-factor

\begin{tabular}{|l|c|} 
Type of Grating & Q factor \\
\hline Fiber Bragg grating & 288.335 \\
\hline Dispersion Compensation Fiber & 284.994 \\
\hline Without any compensation & 80.729 \\
\hline
\end{tabular}

Table 5 depicts the overall comparative Q factor analysis of all three techniques and it is confirmed that the $\mathrm{Q}$ factor is maximum with FBG and least with dispersion compensation fiber. The $\mathrm{Q}$ factor is very poor for nongrating compensation technique.

\section{Graphical representation of FBG vs. DCF}

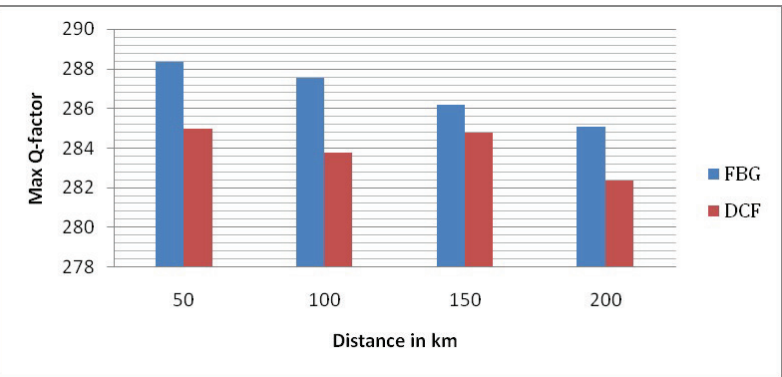

Figure 15: Graphical representation of FBG vs. DCF

\section{Conclusions}

The overall objective of the paper is achieved by mitigating the dispersion present in the optical fiber channel. As a dispersion compensator for a $200 \mathrm{~km}$ longdistance optical communication network, a novel dispersion compensation model incorporating FBG and DCF has been devised in this paper. This paper focuses on the usage of optical grating methods with an $8 \times 1$ WDM MIMO communication system having a $5 \mathrm{Gbit} / \mathrm{s}$ data rate. Since the interference of the signal had its considerable effect on the received output spectrum, the Fiber Bragg grating and dispersion compensation fiber performance were analyzed with a WDM system. The capacity of the design is made maximum and promising equal output response for all users present in the channel.NRZ line coding techniques are analyzed as line codec methods irrespective of Returnto- Zero (RZ) because of the high sensitivity of NRZ. A detailed comparison of the system without grating and with grating is made. After simulation, the Q-factor and BER were determined using the eye-diagram analyzer. The improved Q factor of 288.335 is attained with FBG, 284.994 is achieved for DCF, considering minimum of $0.6 \mathrm{~dB} / \mathrm{km}$ attenuation. The output signal spectrum results from the spectrum analyzer are dispersion-free after compensation with the grating technique. The bit error rate is minimized as much as possible at the receiver. As a result, the suggested dispersion compensator technique enhances Q-factor, reduces bit error rate and transfers a large amount of data, boosting the overall performance of an optical fiber network. 


\section{Conflict of interest}

The author of this document does not have any Conflict of Interest (COI) in publishing this paper.

\section{References}

1. Mohammed, A.N., Okasha, M.N. and Aly, H.M., 2016. A wideband apodized FBG dispersion compensator in long haul WDM systems. J. Optoelectron. Adva. Mater., 18, pp.475-479. https://www. researchgate.net/pofile/ Nazmi-Mohammed/ publication/304381718

2. Karpagarajesh, G., and M. Vijayaraj. "Blocking Probability in All-Optical WDM Network Using IMCA." Circuits and Systems 7, no. 06 (2016): 1068. https://doi.org/10.4236/cs.2016.76090

3. M. Vidmar, "Optical-Fiber Communications: Components and Systems", Informacije MIDEM, vol. 31 (2001), no. 4, pp. 246-251. http://www. midemdrustvo.si/Journal\%20papers/MIDEM_31 (2001)4p246.pdf

4. B. Batagelj, V. Janyani and S. Tomazic, "Research challenges in optical communications towards 2020 and beyond", Informacije MIDEM, vol. 44 (2014), no. 3, pp.177-184. http:// www.midemdrustvo.si/Journal\%20papers/ MIDEM_44(2014)3p177.pdf

5. Khan, S.S.A. and Islam, M.S., 2012. Determination of the best apodization function and grating length of linearly chirped fiber Bragg grating for dispersion compensation. J. Commun., 7(11), pp.840-846. http://www.jocm.us/uploadfile/2013/0422/20130422113251425.pdf

6. M. A. Ilgaz, et al., "A flexible approach to combating chromatic dispersion in a centralized $5 \mathrm{G}$ network", Opto-Electronics Review, 2020, vol. 28, No. 1, pp. 35-42). http://yadda.icm.edu.pl

7. Hu, B.N., Jing, W., Wei, W. and Zhao, R.M., 2010, July. Analysis on Dispersion Compensation with DCF based on Optisystem. In 20102ndinternationalconference on Industrial and Information Systems (Vol. 2, pp. 40-43) IEEE. http://opt.zju.edu.cn/eclass/attachments/2011-10/01-1318924386-55864.pdf

8. Kaler,R.S., Sharma, A.K. and Kamal, T.S., 2002. Comparison of pre-, post-and symmetrical-dispersion compensation schemes for $10 \mathrm{~Gb} / \mathrm{s}$ NRZ links using standard and dispersion compensated fibers. Optics Communications,209(1-3),pp.107-123. https://citeseerx.ist.psu.edu/viewdoc/download? doi=10.1.1.719.9635\&rep=rep1\&type $=$ pdf

9. Kaur, R. and Singh, M., 2016. Dispersion compensation in optical fiber communication system using WDM with DCF and FBG. IOSR Journal of
Electronics and Communication Engineering (IOSRJECE), 11(2), pp.122-30. https://d1wqtxts1xzle7. cloudfront.net/47555751/S110302122130-withcover-page-v2.pdf

10. Karpagarajesh Guruviah, and Helen Anita. "Maximizing the area spanned by the optical SNR of the $5 \mathrm{G}$ using digital modulators and filters." Int. Arab J. Inf.Technol.18,no.3(2021):306-311 https://doi.org/10.34028/iajit/18/3/6

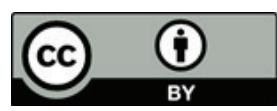

Copyright (c) 2021 by the Authors. This is an open access article distributed under the Creative Commons Attribution (CC BY) License (https://creativecommons.org/licenses/by/4.0/), which permits unrestricted use, distribution, and reproduction in any medium, provided the original work is properly cited.

Arrived: 01. 06. 2021

Accepted: 12. 10. 2021 